\title{
Blended Health Coaching for Work-linked Couples: Coaches' Intervention Fidelity and Empathy Matter!
}

\author{
Christine Busch $^{1} \mathbb{D} \cdot$ Romana Dreyer $^{1} \mathbb{D} \cdot$ Monique Janneck $^{2} \mathbb{D}$
}

Accepted: 28 December 2021 / Published online: 26 January 2022

(c) The Author(s) 2022

\begin{abstract}
Small business owners often work together with their spouses in their business. They blur work-life boundaries and find it difficult to psychologically detach from work, which both jeopardize a satisfying work-life balance (WLB). This paper aims to investigate the mechanisms and outcomes of a coaching intervention for couples to foster their detachment and WLB. We study the role of coaches' intervention fidelity and empathy. A blended coaching format was chosen, i.e., we combined face-to-face with tele-sessions and online courses, thereby using digitalization to keep the coaching flexible to the couples' life situations and for digital support between sessions.

Coaches' behavior in regard to intervention fidelity was observed. Based on these ratings, the clients' sample $(N=42)$ was partitioned into two intervention groups ("high intervention fidelity" vs. "low intervention fidelity") using the adapted study design approach. We also observed coaches' empathy and assessed clients' self-reports at different times up to 4 months after the coaching intervention ended regarding the hypothesized mechanisms of change of the coaching concept and coaching outcomes. We also assessed clients' affinity for technology (ATI) because of the blended format of the coaching. Two-factor ANOVAs with repeated measures showed large effects $(d=1)$ for detachment $(p=.002)$ and middle effects $(d=0.7)$ for WLB $(p=.042)$ up to 4 months after the intervention ended without any interaction effect. Only in the "high intervention fidelity" group did the mechanisms of change and ATI ( $p=.000$ to $p=.036)$ predict general coaching outcomes 4 months after the coaching ceased. Coaches' empathy predicted goal attainment $(p=.004)$ in the "high intervention fidelity" group.

The couple coaching was highly effective in boosting clients' detachment and WLB independent of coaches' intervention fidelity. The assumed change mechanisms of the coaching concept and the ATI were only effective when there was a high degree of intervention fidelity. Coaches should be aware of the conceptual foundations and the core components of their coaching approach.
\end{abstract}

Keywords Coaching $\cdot$ Detachment $\cdot$ Work-life balance $\cdot$ Intervention fidelity $\cdot$ Empathy $\cdot$ Mixed-method approach

Christine Busch

christine.busch@uni-hamburg.de

1 Industrial and Organizational Psychology, Institute of Psychology, University of Hamburg, Von-Melle-Park 5, 20146 Hamburg, Germany

2 THL, Lübeck, Germany 


\section{Blended Gesundheitscoaching für Paare: Interventionstreue und Empathie des Coaches sind von Bedeutung!}

\section{Zusammenfassung}

Kleinunternehmer arbeiten häufig mit ihren Lebenspartnern zusammen im Betrieb. Sie erleben eine extreme Vermengung ihres Arbeits- und Privatlebens und haben häufig Probleme von ihrer Arbeit abzuschalten. Dies ist jedoch für ihre Zufriedenheit mit der Work-Life Balance entscheidend. In diesem Beitrag untersuchen wir mit dieser Zielgruppe ein Coaching zur Förderung des Abschaltens von der Arbeit und Work-Life Balance (WLB). Dabei setzen wir einen Fokus auf das Coachverhalten hinsichtlich Interventionstreue und Empathie. Wir wählten ein Blended Coaching Format, d.h. wir kombinierten Face-to-face mit Tele-Sitzungen und Onlinekursen, um die Digitalisierung für mehr Flexibilität und Unterstützung zwischen den Sitzungen zu nutzen.

Wir beobachteten das Coachverhalten in Bezug auf die Interventionstreue und teilten darauf basierend die Klienten $(N=42)$ im Sinne des „adapted designs“ in zwei Interventionsgruppen auf. Wir beobachteten zudem die Empathie der Coaches. Mittels Fragebögen erfassten wir die Veränderungsmechanismen des Coachingkonzepts und Ergebnisse aus Sicht der Klienten bis zu 4 Monate nach Beendigung des Coachings. Aufgrund des Blended Formats untersuchten wir zudem den Einfluss der Technikaffinität (ATI) der Klienten auf den Coachingerfolg.

Zweifaktorielle ANOVAs mit Messwiederholungen bis zu 4 Monate nach Ende des Coachings zeigten große Effekte für Abschalten von der Arbeit $(p=.002)$ und mittlere Effekte für eine zufriedenere WLB $(p=.042)$ ohne Interaktionseffekte. Nur in der Interventionsgruppe mit hoher Interventionstreue sagten die angenommenen Veränderungsmechanismen und der ATI $(p=.000$ bis $p=.036)$ die Wirksamkeit vier Monate nach Coachingende voraus. Die Empathie der Coaches bestätigte sich als Prädiktor für die Zielerreichung in der Gruppe mit hoher Interventionstreue $(p=.004)$.

Das Paar-Coaching war unabhängig von der Interventionstreue der Coaches hochwirksam. Die angenommenen Veränderungsmechanismen des Coachings und der ATI kamen ausschließlich bei einer hohen Interventionstreue zur Wirkung. Coaches sollten sich der konzeptionellen Grundlagen und der Kernkomponenten ihres Coachingansatzes bewusst sein.

\section{Schlüsselwörter Coaching $\cdot$ Abschalten $\cdot$ Work-Life-Balance $\cdot$ Interventionstreue $\cdot$ Empathie $\cdot$ Mixed-Methods Ansatz}

Due to the general and pandemic-driven trends of digitalization, home office and the associated blurring of worklife boundaries people find it difficult to 'switch-off' after work which impedes a satisfying work-life balance (WLB) (Carlson and Frone 2003). People particularly struggle to psychologically detach from work (hereafter, detachment) when they are faced with high job demands (Steed et al. 2021; Sonnentag 2018). Detachment has been identified in the literature as the most powerful recovery experience (Bennett et al. 2018; Sonnentag and Fritz 2007, 2015). Detachment means refraining from work-related activities during off-job time (e.g., reading work emails), mentally leaving work behind and gaining distance from one's job demands (Sonnentag and Fritz 2007). Scholars and practitioners have recognized that detachment can be enhanced through intervention programs. A recent meta-analysis with 30 (mostly training) detachment intervention studies showed small to medium effects in increasing detachment $(d=0.36)$ on average (Karabinski et al. 2021).

In the present study, we investigated a detachment and WLB coaching intervention in an extreme context in regard to blurred work-life boundaries and detachment: small business owners (SBOs) and their spouses, who often work together in their business (Jurik et al. 2019). They actively manage a business with fewer than 50 employees (Euro- pean Commission 2020). SBOs live for and with their business (physically and mentally), blur work-life boundaries (Helmle et al. 2014), and show enormous difficulties to detach from their business (Kollmann et al. 2019). At the same time, prevention providers hardly reach them for mental health interventions (Hogg et al. 2021). Small businesses have low take up of health promotion programs, in general (Hasle and Limborg 2006; McCoy et al. 2015).

The coaching has three theory-driven conceptual foundations. First, it is a couple coaching to consider the context of SBOs and their spouses as work-linked couples when setting goals (Orehek and Forest 2016) and when fostering individual behavior change toward detachment and WLB (e.g., Hobfoll and Hobfoll 1994; Nowack 2017; Park and Haun 2017). Second, the coaching is based on the resultoriented coaching concept (Greif 2008) which stresses result-oriented self-reflection as the coaching mechanism of change. Third, it is based on the Zürich Resource Model (ZRM; Storch and Krause 2017). It is a self-management training concept based on neuroscientific theories and findings (Storch 2004). These three conceptual foundations will be outlined in the coaching concept section of this article. Furthermore, we applied a blended format ( 3 face-to-face and 2 video-based tele-sessions, 3 online courses and an online diary) to offer sustainable coaching in a time of in- 
creased technology use. A recent 8-month wait-list evaluation study of this blended coaching concept with SBOs and their spouses showed that participants in the intervention group experienced more detachment and were less exhausted than those in the control group four months after the intervention had ceased. Spousal support during coaching was the main mechanism of change. Beyond that, the working alliance between coach and client did not play a success-predictive role (Busch et al. 2021).

In this study we look at the implementation processes (Nielsen and Randall 2013), i.e. coaches' behavior in relation to intervention fidelity (the extent to which the coach delivers the intervention as intended (Murphy and Gutman 2012)) and in relation to empathy (Will et al. 2016). We study the influence of coaches' intervention fidelity on the coaching mechanisms of change (e.g., spousal support during coaching) and coaching outcomes (e.g., goal attainment). Furthermore, we study the influence of coaches' empathy on coaching outcomes. As intervention-specific outcomes we integrate clients' intervention receipt (whether the client comprehends and uses the intervention skills during the session) (Borrelli et al. 2005), detachment and WLB.

Our study seeks to make several important theoretical and methodological contributions to the coaching literature. First, we contribute to coaching research by investigating implementation processes and coaching mechanisms of change that impact coaching effectiveness. Second, we focus on coaches' behavior, i.e., the under-investigated intervention fidelity (Gearing et al. 2011) and empathy of coaches (Will et al. 2016). Third, we follow the call for transferring the ZRM to coaching research (Storch 2004) and for researching digitalized health interventions (Howarth et al. 2018) and online coaching (BerningerSchäfer 2018). Fourth, we contribute to coaching research by using the adapted study design approach (Randall et al. 2005), and by using mixed methods (observational and self-report data, Bryman 2006). Last, we answer the call for worksite health promotion research in small businesses (Gerhardt et al. 2019) and with entrepreneurs (Stephan 2018). We hope to guide future coaching intervention studies that aim to contribute to the literature.

In the following section, we first introduce coaches' behavior with regard to intervention fidelity and empathy as implementation process factors before we present the conceptual foundations of the couple coaching intervention and its mechanisms of change. Finally, we introduce the general and intervention-specific coaching outcomes.

\section{Coaches' Intervention Fidelity and Empathy}

When researching interventions, scholars ideally investigate context, mechanisms, outcomes, as it is outlined in the realist evaluation approach (Pawson and Tilley 1997), and implementation processes (Busch et al. 2021; Nielsen and Randall 2013). The implementation process model for organizational health interventions by Nielsen and Randall (2013) distinguishes between design and implementation, e.g., coaches' intervention fidelity (Murphy and Gutman 2012) and coaches' empathy (Will et al. 2016), and participants' mental models, e.g., clients' affinity for technology interaction in the implementation of a digital intervention (Schueller et al. 2017). In this section, we first outline coaches' intervention fidelity and empathy as implementation process factors before we present clients' affinity for technology interaction as participants' mental models in the next section.

Intervention fidelity is the extent to which core components of the intervention are delivered by the interventionist as it was intended by the authors of the intervention (Gearing et al. 2011). Careful consideration of intervention fidelity is needed when mechanisms of change are being investigated. Further it helps to accurately interpret study findings, revise interventions for future studies, and increase internal validity, statistical power and effect size by reducing unintended variability. Enhancing intervention fidelity also has the effect of increasing external validity, as a high degree of intervention fidelity is needed for both study replication and for generalization of the intervention to other contexts (Borrelli et al. 2005). According to Gearing et al. (2011) four core components should be considered: (1) the first component is the use of intervention manuals as a means to improve the integrity of interventions and provide interventionists with intervention protocols, as well as parsing intervention integrity into the interventionists' adherence and competence. Intervention manuals are necessary to ensure that multiple providers administer the same intervention in the same manner. Theories, goals and strategies are outlined in an intervention manual, including how a program should be organized and delivered, and the role and responsibilities of the providers. (2) The second component of fidelity is training the interventionist. For an intervention to be implemented with fidelity, adequate training and supervision of interventionists during the course of the intervention are required. (3) The third core component of fidelity is intervention delivery. It is the heart of fidelity, as it involves the measurement of fidelity during the course of the intervention with a focus on the interventionists' behavior. Behaviors that are unique to the intervention and essential to the specific intervention are of special interest (i.e., asking the clients to engage in spousal social support 
during coaching). (4) The fourth component is the monitoring of the clients' intervention receipt. This component incorporates elements that focus on whether participants comprehend and use the intervention skills during the sessions and the extent to which participants are engaged and adherent with the content of the intervention. We see intervention receipt as the immediate goal of the coaching or as the most proximal specific outcome (Greif 2017; Semmer 2011; see also Kirkpatrick's evaluation framework 1976) rather than as a component of intervention fidelity. Only when a coach manages to deliver the intervention in the expected way, clients will be able to use the intended intervention skills. Thus, intervention receipt can also be seen as a "manipulation check", if the intervention reaches its goals based on the chosen theoretical concepts and methods. This leads us to our first hypothesis:

Hypothesis 1: When coaches demonstrate high intervention fidelity, their clients' intervention receipt is higher compared to clients' intervention receipt when coaches demonstrate low intervention fidelity.

Coaches ideally not only deliver the coaching concept according to the manual, i.e., to the theoretical foundations, components and methods, but coaches should also show empathic behavior. Coaches' empathy is vital for establishing a trusting coach-client relationship and essential for effective communication (Nicolai et al. 2007), for a strong working alliance (Baron and Morin 2009; de Haan et al. 2011) and coaching success (Will and Kauffeld 2018; Will et al. 2016). Empathy is generally seen as a two-dimensional concept with affective and cognitive components. Empathy in coaching is focused on the cognitive aspect of understanding the client's perspective and the behavioral ability to communicate this understanding to the client (Nicolai et al. 2007; Will and Kauffeld 2018; Will et al. 2016). Initial findings from a recent study evaluating the couple coaching stressed that the working alliance between coach and clients is not success-predictive (Busch et al. 2021). Thus, we did not have a hypothesis about coaches' empathy in this couple coaching intervention but wanted to investigate its role as a coaching success factor:

Research question 1: Does coaches' empathic behavior have any influence on coaching outcomes?

\section{Clients' Affinity for Technology Interaction}

With regard to the implementation process model (Nielsen and Randall 2013), participants' mental models play a predictive role in occupational health interventions. Our blended coaching mixes face-to-face elements with digital offers, such as tele-coaching and online courses. Therefore, we see clients' affinity for technology interaction (ATI) as the crucial clients' mental model (Busch et al. 2021). It is a person's propensity to naturally interact with technical systems (Franke et al. 2019). In a recent evaluation study of this coaching format, SBOs and coaches reported in interviews that when the SBOs experienced increasing workload, the online courses were the first part of the coaching that they skipped or postponed. Furthermore, some of the participants had problems connecting to the internet or problems with the interface (Busch et al. 2021). However, participants with a higher ATI or a generally more positive attitude toward technology, are more likely to succeed in online intervention formats and to be able to solve possible technical problems (e.g., Backhaus et al. 2019). If the coaches deliver the coaching as intended, the coaches had made the relevance of the online courses and the online diary clear and built upon the knowledge and exercises of the online courses and diary during the following coaching sessions. Thus, we expected clients' ATI to be a predictive factor for coaching outcomes when the coaches deliver the intervention as intended.

Hypothesis 2: When coaches demonstrate high intervention fidelity, client's ATI predicts coaching outcomes.

\section{The Coaching Concept and Its Mechanisms of Change}

The coaching intervention in this study has three theorydriven conceptual foundations. First, the present couple coaching intervention follows an interdependent approach in working on individual goals while the spouse being present and supportive. Small business owners and their spouses face highly integrated life-domains and evince interdependencies in setting and pursuing health-related goals (Dreyer and Busch 2021). Spouses in general have strong influences on individual recovery experiences (Park and Haun 2017; Park and Fritz 2014), WLB (Helmle et al. 2014) and behavior change in general (Nowack 2017). As Hobfoll and Hobfoll (1994) outlined from the perspective of conservation of resources (COR) theory (Hobfoll 1989), spouses act interdependently and coordinate their actions to protect and build up individual and shared resources, such as detachment experiences. Haun et al. (2017) found that the resource of a partner's social support attenuated the relationship between time pressure and detachment. When the coach manages to deliver the intervention as intended, the coach stimulates spousal support during coaching. Counseling research supports to consider the social support climate of clients for engaging in behavior change (Nowack 2017). Relationship researchers have long recognized the impor- 
tance of spousal social support for shaping goal pursuits on the basis of goal systems theory (Orehek and Forest 2016). Thus, we expected the coaching intervention to work successfully when delivered as intended by activating spousal social support.

Hypothesis 3: When coaches demonstrate high intervention fidelity, client's spousal social support during the coaching process predicts their coaching outcomes.

Second, the coaching intervention is based on the resultoriented coaching concept, which defines coaching as an intensive and systematic promotion of result-oriented self-reflection to improve the achievement of self-congruent goals or for conscious self-change and self-development (Greif 2008, S. 59). Result-oriented are self-reflections "if the person thereby develops consequences for future actions or self-reflections" (Greif 2008, S. 40). They help developing self-congruent goals and predict goal attainment (Behrendt and Greif 2018; Grant and O'Connor 2018; Greif 2007, 2008). Reflecting and ruminating on personal thoughts and feelings is negatively related to constructive problem-solving and goal attainment and positively related to anxiety and stress reactions (Grant 2003; Grant et al. 2002). Thus, we expected the coaching intervention to work successfully when delivered as planned by activating result-oriented selfreflection.

Hypothesis 4: When coaches demonstrate high intervention fidelity, client's result-oriented self-reflection predicts their coaching outcomes.

Third, we transferred the neuroscientific based self-management training concept of the ZRM (Storch 2004) to this couple coaching. With regard to defining and setting selfcongruent goals and actions, the ZRM refers to the somatic marker hypothesis (Damásio 1998). This hypothesis postulates that we use emotion-based signals generated from the body when appraising different response options for a decision. The emotional memory of an experience with its somatic markers represents the self-system (Kuhl et al. 2015; Storch 2004). Decisions for setting goals that include somatic markers are self-congruent, and these goals lead to success more frequently than goals with lower self-congruence. The strong positive affect that reveals a somatic marker is indicative of self-congruence or intrinsic motivation (Deci and Ryan 2012; Kuhl et al. 2015). Thus, we expected the coaching intervention to work successfully when delivered as planned through activating positive affect:

Hypothesis 5: When coaches demonstrate high intervention fidelity, client's positive affect predicts their coaching outcomes.

\section{Coaching Outcomes}

Coaching scholars distinguish general and interventionspecific coaching outcomes. Coaching satisfaction and the degree of goal attainment are general and key outcome measures in coaching research (Greif 2017, 2007; Spence 2007). Intervention-specific outcomes assess the substantive objectives of interventions (Greif 2007, 2017) and are divided into proximal and distal outcomes (Semmer 2011). Intervention receipt as the most proximal specific outcome was referred to above and led us to develop our first hypothesis. More distal outcome measures for this couple coaching intervention are detachment and WLB.

SBOs and their spouses participate in the coaching to better detach from their business and for a satisfying WLB (Carlson and Frone 2003). WLB is an individual's evaluation of the fulfilment of different roles and goals in all life domains. Activities to refuel resources as a counterbalance to resource-draining life demands are beneficial to satisfaction with WLB (Syrek et al. 2011). Individuals are seen as active creators of their detachment experiences (de Bloom et al. 2020) and of their WLB (Sturges 2012). Based on COR theory (Hobfoll 1989; Hobfoll and Hobfoll 1994), spouses act interdependently and coordinate their actions to protect and build up individual and shared resources, such as detachment experiences. When a coach delivers the intervention as intended, clients change their attitude and behaviors to counterbalance their high job demands by integrating individual or joint detachment experiences into their daily life that is aligned with their partners needs and supported by their partners. Thus, when the coach demonstrate high intervention fidelity, the coaching is expected to help participants better detach from work and to be effective in increasing their WLB:

Hypothesis 6: When the coach delivers the intervention as intended, clients will show an increase in detachment over time in contrast to those clients whose coach demonstrates low intervention fidelity.

Hypothesis 7: When the coach delivers the intervention as intended, clients will show an increase in WLB over time in contrast to those clients whose coach demonstrates low intervention fidelity.

\section{Methods}

\subsection{Design and Procedure}

We considered the context of SBOs and their spouses by involving the regional networks in which SBOs regularly act, in particular regional prevention providers and trade guilds of small businesses. SBOs and their spouses were in- 
vited by their trade guilds to attend an information session. Coaches of the prevention providers and the people of the trade guilds provided information about the couple coaching intervention. We ran an online or paper-pencil pretest before the beginning of the intervention (Time 1 (T1)), an online or paper-pencil posttest four months after the intervention ended (Time 2 (T2)), and a paper-pencil follow-up test in the transfer session four months after T2 (Time 3 (T3)). The participants were asked to fill out paper-pencil questionnaires at the end of each session (Times (T) 1.1, $1.2,1.3,1.4$, and 1.5). We videotaped each session to be able to observe coaches' behavior and clients' intervention receipt. Participants were informed that study participation was voluntary and that their anonymity would be protected. They gave their informed consent to participate in this research. The local ethics committee assessed the research as acceptable. We used an adapted design (Randall et al. 2005) that incorporated the measurement of intervention fidelity to partition the participant sample into two intervention groups (IG1 vs. IG2). Clients in the coaching intervention that was delivered by the coaches as intended belong to IG1, the "high intervention fidelity" group while the others belong to IG2, the "low intervention fidelity" group.

\subsection{Intervention Manual and Train-the-Coach Workshop}

We developed a written coaching manual that includes theories, descriptions of the sessions, strategies, methods, materials and links to the online courses and the online diary. The number, lengths and spacing of sessions are described in the manual (Busch and Dreyer 2020). The blended couple coaching starts with a one-hour first-contact session to establish contact and to provide information about the coaching (tele-)sessions, online diary, courses, questionnaires and videotapes. The first coaching session is a threehour face-to-face session followed by an online diary to stimulate result-oriented self-reflection. Sessions two and five are also face-to-face-sessions. Sessions three and four are designed as tele-sessions. Four months later, a short face-to-face transfer session is designed to remind the participants of their coaching goals and to allow them to complete follow-up tests (T3). Fig. 1 offers an overview of the blended couple coaching. The variables and measurement times in Fig. 1 will be outlined in the measures section (see Fig. 1).

Sessions two, three and four are combined with online courses. The online courses cover information and interactive exercises that help the participants reflect on their situation, behaviors and goals. We designed a stereotypical couple of "personas" (Cooper et al. 2003) to provide examples and inspiration. To illustrate the next step within coaching, the persona-couple set health-related goals, seek resources and plan specific behavior. Thus, the participants are prepared for the coaching sessions and are asked to apply the methods to develop their goals.

The involved 11 (six female) coaches were experienced self-employed coaches that worked for the involved prevention provider on a contract basis. They participated in a one day "train-the-coach" workshop provided by the first and second authors and were supervised by an experienced interventionist of the prevention provider and the first and second authors throughout the whole course of the intervention. In IG1 were four female coaches and one male coach while in IG2 were two female coaches and four male coaches.

\subsection{Participants}

The study included 42 participants (or 21 couples). The mean age was 52 years $(S D=6.6$, ranging from 32 to 66 years). The participants were married for 18.5 years on average ( $S D=9.4$, ranging from 3 to 32 years). The participating owners employed 13.7 people on average $(S D=14.5$, ranging from zero to 50 employees). Twenty-six participants (or 13 couples) had no children under 14 years of

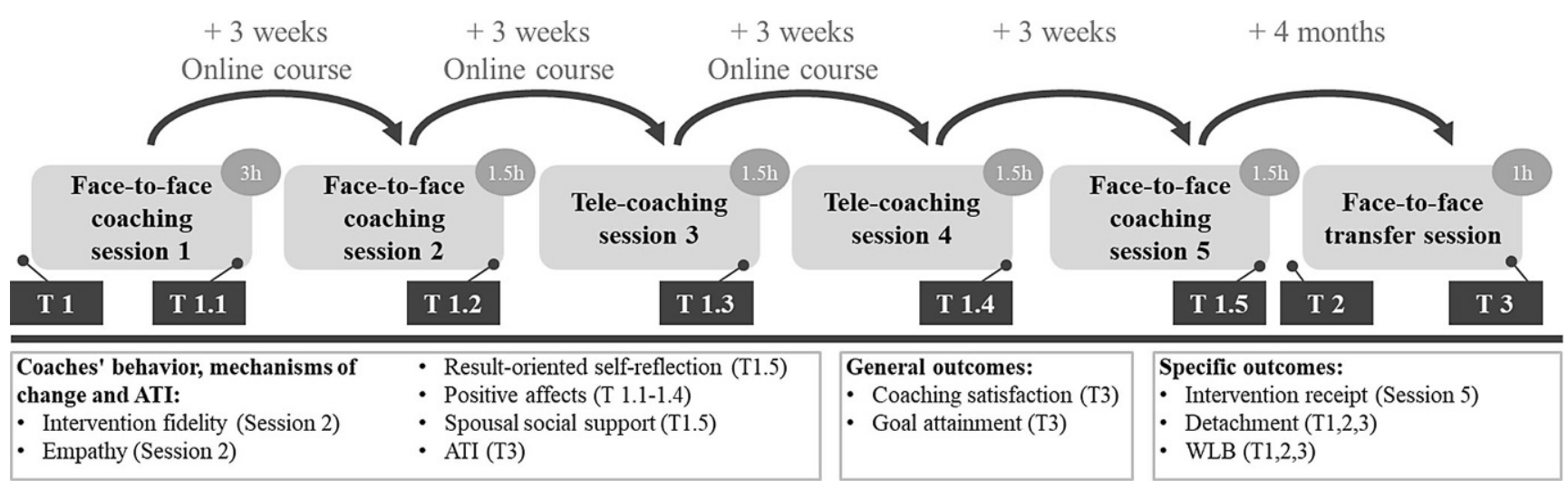

Fig. 1 The Blended Couple Coaching with variables and measurement times (T1, T1.1, T1.2, T1.3, T1.4, T1.5, T2, T3) 
age. Fourteen participants (or 7 couples) had one or two children under 14 years of age. Twenty-eight participants had vocational training, and nine had a university degree. Twenty-three participants (19 males) were official business owners and worked an average of 52.8 hours (hr) per week $(S D=2.2$, ranging from 30 to $65 \mathrm{hr}$ ). Eleven participants (one male) were employed in the businesses of their spouses and worked an average of $29.7 \mathrm{hr}$ per week ( $S D=4.5$, ranging from 5 to $50 \mathrm{hr}$ ). Three participants (one male) were employed by another company but supported their spouses in their businesses. Five women were employed by another company and did not support their spouses in their businesses. We used $t$ tests to compare the two intervention groups in terms of age, years of marriage, number of employees and working hours as sociodemographic variables. We found significant differences for working hours $(p=.032)$ and years of marriage $(p=.009)$. In IG1, participants worked $38.7 \mathrm{hr}$ per week (men $50 \mathrm{hr}$; women $22 \mathrm{hr}$ ) on average $(S D=17.4)$ and they were married for 14.3 years on average $(S D=7.4)$. In IG2, participants worked $50.5 \mathrm{hr}$ per week (men $59 \mathrm{hr}$; women $39 \mathrm{hr}$ ) on average $(S D=13.4)$ and were married for 21.9 years on average $(S D=9.6)$.

\subsection{Measures}

Intervention Fidelity To assess the heart of intervention fidelity, the intervention delivery, we asked the coaches to videotape all coaching sessions. We monitored the delivery of sessions two, four and five. Session two targets the "crossing of the Rubicon" from the motive to the intention by finding and setting self-congruent attitude goals with the method called "inner team" (Schulz von Thun 2019). In session four, the participants' attitude goals are transferred to behavioral implementation intentions combined with mental contrasting (Oettingen and Reininger 2016). In session five the participants' implementation intentions are strengthened to cope with stressful transfer situations. We did not monitor the delivery of session one because initial coaching sessions should be avoided for studying coaches' behavior (Will et al. 2016). We skipped session three because it focuses on embodiment exercises which are difficult to videotape. Three psychology students ${ }^{1}$ were trained and supervised by the first author to independently assess and rate the delivery in session two for each of the seven parts ( 1 introduction, 2 imagination exercise, 3 attitude goal explanation, 4 inner team, 5 spousal and family support, 6 goal formulation, 7 closing) on a 5point Likert-type scale $(1=$ not at all, $2=$ delivered with a goal or method other than what is written in the manual, $3=$ delivered with the same goals and methods as what is written in the manual, but not in the correct manner

${ }^{1}$ Kim van den Anker, Teresa Martin Pelegrina, Jonas Riege.
$4=$ delivered with goals and methods as intended in a correct manner, and 5=exactly delivered word-for-word). To assess whether the raters provided consistency in their ratings across the different coach-client relations (i.e., interrater reliability), we calculated two-way random intraclass correlations (ICCs) with absolute agreement (average measures) between the raters (McGraw and Wong 1996). The ICCs for the seven parts of session two yielded values of 0.985 ( $p=.000), 0.986(p=.000), 0.944(p=.000), 0.932$ $(p=.000), 0.900(p=.000), 0.969(p=.000)$ and 0.762 $(p=.000)$, indicating excellent agreement among the three raters for the first six parts and good agreement for the seventh part (Koo and Li 2016). Analyses of variance (ANOVA) with repeated measures showed significant differences in delivery between the seven parts of session two: $F(3,97,146,91)=10.87 p=.000$. Part six (goal formulation) was delivered significantly worse than all the other parts. The coaches had problems to help the participants formulate an attitude goal after exploring their motives. Part 5 (spousal support) was also not delivered as intended $(<3)$ on average. The coaches did not carefully stimulate spousal support in this phase of the coaching.

One of the three raters ${ }^{2}$ rated the intervention delivery of sessions four and five. ANOVAs with repeated measures showed significant differences between the delivery of the different parts of session four: $F(2.97,62.33)=2.93$, $p=.041$. Post hoc tests did not show any significant differences, but only the initial part, another part and the closing part were delivered at least with goals and methods as intended, on average $(\geq 3)$. The main parts were not delivered as intended. ANOVAs with repeated measures showed no significant differences between the delivery of the different parts of session five: $F(2.37,49.86)=1.30, p=.283$. ANOVA with repeated measures showed significant differences between the delivery of sessions two, four and five: $F(1.46,30.64)=6.49, p=.009$. Post-hoc test showed significant differences between session two and both sessions four and five ( $p=.038$ and $p=.003$, respectively). Sessions four and five were delivered in a significantly worse manner than session two, on average. We decided that the participants who experienced coaching session two delivered with the same goals and methods as intended, even if not in a correct manner $(\geq 3)$ belong to IG1 $(n=18)$, and the others to IG2 $(n=24)$ to guarantee a similar amount of coaching in each group. Furthermore, developing an attitude goal toward detachment and WLB is a core component of this coaching intervention and the prerequisite for all of the following sessions, and session two was delivered in a significantly better manner than sessions four and five.

2 Teresa Martin Pelegrina. 
Intervention Receipt Participants' intervention receipt was observed in session five (see Fig. 1) by one psychology student ${ }^{3}$ and the first author. We rated the number and quality of activated resources, spousal support and implementations of the attitude goal. Three items were answered on a 5-point Likert-type scale $(1=$ not at all; $5=$ high number and quality) with $100 \%$ agreement. Cronbach's alpha was 0.72 .

Empathy by the coach was assessed in session two (see Fig. 1) using the 6-item subscale of the adapted Rating Scale for the Assessment of Empathic Communication in Medical Interviews (REM; Meinecke and Kauffeld 2019; Nicolai et al. 2007). Sample items include "Did the coach show understanding of the client's point of view?", "Did the coach try to put him/herself in the position of the client?", and "Did the coach show interest in the client's opinion?". All items were answered on a 7-point Likert-type scale. The two endpoints of each item were described as behavioral terms such as indicating that the coach showed (1) no interest or (7) much interest. We used additional behavioral anchors to facilitate the rating process (e.g., "frequently cut the client off" vs. "frequently asked the client to express his or her opinions") in accordance with former studies (Meinecke and Kauffeld 2019).

Raters for each trial were two psychology students ${ }^{4}$ who independently rated the coaches' empathy towards each of the clients by watching to the video recordings of session two and using a paper-pencil template. The students were trained and supervised by the first author. Session two is divided in seven parts, of which five could be rated because in these parts, the coach should show empathic behavior. To assess whether the raters provided consistency in their ratings of empathy across the different coach-client relations (i.e., interrater reliability), we calculated two-way random ICCs with absolute agreement (average measures) between the raters (McGraw and Wong 1996). The ICCs for the observed five parts of session two yielded values of $0.800(p=.000), 0.913(p=.000), 0.866(p=.000)$, $0.905(p=.000), 0.947(p=.000)$, indicating good to excellent agreement among the raters (Koo and Li 2016). The average internal consistency yielded a value of 0.94 (Cronbach's $\alpha$ ). In order to explore possible differences in the extent of coaches' empathic communication across the five parts, we calculated repeated ANOVAs. The results showed no significant differences between the five parts $(F(1,74,29,64)=2.60, p=.098)$, indicating that the extent of expressed empathy was rather stable across the coaching session. We used the mean empathy score across the five parts of the session. Following recommendations from the

\footnotetext{
3 Teresa Martin Pelegrina.

${ }^{4}$ Kim van den Anker, Teresa Martin Pelegrina.
}

behavioral observation literature (Yoder and Symons 2010), we also used the mean empathy rating of the two raters.

ATI was measured with the 9-item Franke et al. (2019) scale in the transfer session at T3 (see Fig. 1). A sample item is, "I like testing the functions of new technical systems." Three items were reversed formulated. A sample item is, "It is enough for me to know the basic functions of a technical system.” Items were answered on a 6-point Likert-type scale ( $1=$ completely disagree; $6=$ completely agree). Cronbach's alpha was 0.89 .

Spousal social support during coaching was assessed using paper-pencil format at the end of the last coaching session (T1.5, see Fig. 1) with the 5-items scale according to the contents of the five coaching sessions: "My spouse supported me during the coaching (1) '... to reflect my actual needs.' (2) '... to develop my action-oriented goal.' (3) '... to develop resources that support my goal attainment.' (4) '... to improve my competencies to attain my goal in type B situations.' and (5) '... to improve my competencies to attain my goal in type C situations."” (Busch et al. 2021). Items were answered on a 5-point Likert-type scale $(1=$ not at all; $5=$ completely). Cronbach's alpha was 0.92 .

Result-oriented self-reflection was measured with the 3-item Greif and Berg (2011) scale at T2 (see Fig. 1). A sample item is "During the coaching, I thought about my personal needs, goals, and norms, and I made a plan for how to reach them". The response format was a 5-point Likert-type scale ( $1=$ not at all; $5=$ completely). Cronbach's alpha was 0.89 .

Positive affect was measured at the end of each of the first four coaching sessions (T1.1-1.4, see Fig. 1) with 10 items, including "active", "strong", "interested", "alert", "attentive", "joyful", "enthusiastic", "inspired", "proud", and "determined", of the positive affect dimension of PANAS, which operationalizes approach-oriented positive emotional feelings (Krohne et al. 1996; Watson et al. 1988). The response format was a 5-point Likert-type scale $(1=$ not at all; $5=$ most). Cronbach's alphas were 0.94, 0.93, 0.95 and 0.93 , for Times 1.1-1.4, respectively.

General coaching outcomes were assessed in the transfer session at T3 (see Fig. 1) (Greif 2007, 2017; Spence 2007). Coaching satisfaction was assessed by each participant with the Runde $(2003,2016)$ item "How satisfied are you with the coaching?" using a 6-point Likert-type scale ( $1=$ very satisfied; $6=$ very dissatisfied). Goal attainment was assessed with the Runde $(2003,2016)$ item "How high in percentage do you rate your personal goal attainment?"

Specific distal coaching outcomes were measured at $\mathrm{T} 1$, T2, and T3 (see Fig. 1) (Greif 2007, 2017; Semmer 2011). Detachment was assessed with the four items from the Sonnentag and Fritz (2007) scale. Items were answered on a 5point Likert-type scale $(1=$ strongly disagree; $5=$ strongly agree). A sample item is "During leisure time, I don't 
Table 1 Descriptive Statistics and Correlations of the Study Variables Coaches' Empathy, Clients' Affinity for Technology Interaction (ATI), Mechanisms of Change (Spousal Support, Self-reflection, Positive Affect), Coaching Satisfaction and Goal Attainment

\begin{tabular}{|c|c|c|c|c|c|c|c|c|c|c|c|}
\hline \multicolumn{2}{|c|}{ Variable } & \multirow{2}{*}{$\frac{n}{40}$} & \multirow{2}{*}{$\frac{M}{5.37}$} & \multirow{2}{*}{$\frac{S D}{0.83}$} & \multirow[b]{2}{*}{-} & \multirow[t]{2}{*}{2} & \multirow[t]{2}{*}{3} & \multirow[t]{2}{*}{4} & \multirow[t]{2}{*}{5} & \multirow[t]{2}{*}{6} & \multirow[t]{2}{*}{7} \\
\hline 1. & $\begin{array}{l}\text { Coaches' empathy } \\
\text { (Session 2) }\end{array}$ & & & & & & & & & & \\
\hline 2. & ATI (T3) & 31 & 3.59 & 0.96 & .14 & - & & & & & \\
\hline 3. & Spousal support (T1.5) & 42 & 4.10 & 0.68 & .09 & .32 & - & & & & \\
\hline 4. & Self-reflection (T2) & 40 & 3.86 & 0.75 & .13 & $.52 * *$ & $.65^{* *}$ & - & & & \\
\hline 5. & $\begin{array}{l}\text { Positive affect } \\
\text { (T1.1-T1.4) }\end{array}$ & 42 & 3.63 & 0.57 & .07 & .36 & $.62 * *$ & $.52 * *$ & - & & \\
\hline 6. & $\begin{array}{l}\text { Coaching satisfaction } \\
\text { (T3) }\end{array}$ & 34 & 1.76 & 1.33 & -.23 & -.05 & $-.54 * *$ & -.31 & $-.37 *$ & - & \\
\hline 7. & Goal attainment (T3) & 34 & 64.32 & 23.31 & $.38^{*}$ & .29 & .34 & 0.34 & $.55^{* *}$ & $-.57 * *$ & - \\
\hline
\end{tabular}

$* p<0.05, * * p<0.01$ (two-tailed)

Table 2 Regression of Coaches' Empathy, Affinity for Technology Interaction (ATI), Mechanisms of Change (Spousal Support, Self-reflection, and Positive Affect) on Coaching Satisfaction and Goal Attainment with Participants in the High Intervention Fidelity Group IG1

\begin{tabular}{|c|c|c|c|c|c|c|}
\hline \multirow{2}{*}{$\frac{\text { Variable }}{\text { Coaching Satisfaction (T3) }}$} & \multirow[t]{2}{*}{$B$} & \multirow[t]{2}{*}{$S E$} & \multirow[t]{2}{*}{$t$} & \multirow[t]{2}{*}{$p$} & \multicolumn{2}{|c|}{$95 \%$ CI for $B$} \\
\hline & & & & & & \\
\hline Coaches' empathy (Session 2) & -0.68 & 0.36 & -1.87 & .080 & {$[-1.45$} & $0.09]$ \\
\hline ATI (T3) & -0.79 & 0.24 & -3.27 & .005 & {$[-1.31$} & $-0.28]$ \\
\hline Spousal support (T1.5) & -1.14 & 0.25 & -4.59 & .000 & {$[-1.67$} & $-0.62]$ \\
\hline Self-reflection (T2) & -0.80 & 0.30 & -2.65 & .018 & {$[-1.44$} & $-0.16]$ \\
\hline Positive affect (T1.1-T1.4) & -0.94 & 0.40 & -2.33 & .033 & {$[-1.79$} & $-0.08]$ \\
\hline \multicolumn{7}{|l|}{ Goal Attainment (T3) } \\
\hline Coaches' empathy (Session 2) & 23.57 & 6.99 & 3.37 & .004 & {$[8.75$} & 38.39] \\
\hline ATI (T3) & 17.83 & 5.58 & 3.19 & .006 & {$[5.99$} & 29.67] \\
\hline Spousal support (T1.5) & 21.34 & 6.82 & 3.13 & .006 & {$[6.88$} & 35.79] \\
\hline Self-reflection (T2) & 16.47 & 7.16 & 2.30 & .036 & {$[1.21$} & 31.72] \\
\hline Positive affect (T1.1-T1.4) & 28.62 & 7.88 & 3.63 & .002 & {$[11.92$} & 45.32] \\
\hline
\end{tabular}

Note. $n=17$, except for self-reflection $n=16$.

think about work at all". Cronbach's alphas were 0.93 at T1, 0.84 at $\mathrm{T} 2$, and 0.95 at $\mathrm{T} 3$, respectively. WLB was measured with the five items from the Syrek et al. (2011) scale. Items were answered on a 6-point Likert-type scale $(1=$ totally disagree; $6=$ completely agree). A sample item is "I manage to achieve a good balance between stressful and restful activities in my life". Cronbach's alphas were 0.92 at T1, 0.91 at T2, and 0.92 at T3, respectively. In Fig. 1 you see all the above-mentioned variables and measurement times.

\subsection{Data Analysis}

Independent-samples t-tests were conducted to compare clients' intervention receipt in the "high intervention fidelity" and "low intervention fidelity" group (IG1 vs. IG2) (H1). To test the research question and our hypotheses that ATI (H2), spousal support during coaching (H3), resultoriented self-reflection (H4) and positive affect (H5) predict general coaching outcomes (coaching satisfaction and goal attainment) in the "high intervention fidelity" group (IG1) but not in the "low intervention fidelity" group (IG2), we used simple regression analyses due to the small sample size. We tested the hypotheses that coaching is effective on detachment and WLB over time in the "high intervention fidelity" group (IG1) but not in the "low intervention fidelity" group (IG2) (H6 and H7) using two-factor ANOVAs with repeated measures.

\section{Results}

Our first hypothesis (H1) stated that clients' intervention receipt is higher when coaches demonstrate high intervention fidelity compared to clients' intervention receipt when coaches demonstrate low intervention fidelity. There were significant differences in the intervention receipt scores between the "high intervention fidelity" group (IG1) $(M=3.60, S D=0.81)$ and the "low intervention fidelity" group (IG2) $(M=2.03, S D=0.48), t(24)=-5.53, p=.000$, supporting Hypothesis 1.

Concerning our research question (RQ) regarding the influence of coaches' empathy on coaching success, the 
Table 3 Regression of Coaches' Empathy, Affinity for Technology Interaction (ATI), Mechanisms of Change (Spousal Support, Self-reflection, and Positive Affect) on Coaching Satisfaction and Goal Attainment with Participants in the Low Intervention Fidelity Group IG2

\begin{tabular}{|c|c|c|c|c|c|c|}
\hline Variable & $B$ & $S E$ & $t$ & $p$ & \multicolumn{2}{|c|}{$95 \% \mathrm{CI}$ for $B$} \\
\hline \multicolumn{7}{|l|}{ Coaching Satisfaction (T3) } \\
\hline Coaches' empathy (Session 2) & -0.04 & 0.51 & -0.07 & .945 & {$[-1.15$} & $1.08]$ \\
\hline ATI (T3) & 0.62 & 0.45 & 1.37 & .198 & {$[-0.38$} & $1.62]$ \\
\hline Spousal support (T1.5) & -1.01 & 0.72 & -1.40 & .183 & {$[-2.57$} & $0.54]$ \\
\hline Self-reflection (T2) & -0.35 & 0.74 & -0.48 & .640 & {$[-1.95$} & $1.24]$ \\
\hline Positive affect (T1.1-T1.4) & -0.67 & 0.71 & -0.95 & .359 & {$[-2.19$} & $0.85]$ \\
\hline \multicolumn{7}{|l|}{ Goal Attainment (T3) } \\
\hline Coaches' empathy (Session 2) & 1.60 & 6.76 & 0.24 & .816 & {$[-13.12$} & $16.33]$ \\
\hline ATI (T3) & -3.99 & 4.75 & -0.84 & .418 & {$[-14.44$} & $6.45]$ \\
\hline Spousal support (T1.5) & -8.87 & 9.92 & -0.89 & .386 & {$[-30.15$} & 12.41] \\
\hline Self-reflection (T2) & 1.91 & 8.92 & 0.21 & .834 & {$[-17.37$} & 21.19] \\
\hline Positive affect (T1.1-T1.4) & 12.38 & 9.05 & 1.37 & .193 & {$[-7.03$} & 31.78] \\
\hline
\end{tabular}

Note. Coaches' empathy $n=13$, ATI $n=12$, spousal support $n=15$, self-reflection $n=14$, positive affect $n=15$.

Table 4 Means, Standard Deviations, and repeated Analyses of Variance (ANOVA) Statistics for Detachment and Work-Life Balance (WLB)

\begin{tabular}{|c|c|c|c|c|c|c|c|c|}
\hline \multirow[t]{2}{*}{ Variable } & \multicolumn{2}{|c|}{ IG1 $(n=17)$} & \multicolumn{2}{|c|}{ IG2 $(n=16)$} & \multirow[t]{2}{*}{ ANOVA } & \multirow[t]{2}{*}{$p$} & \multirow[t]{2}{*}{$\eta^{2}$} & \multirow[t]{2}{*}{$d$} \\
\hline & $M$ & $S D$ & $M$ & $S D$ & & & & \\
\hline Detachment T1 & 3.54 & 0.75 & 2.67 & 0.83 & $F(1.6,49.73)$ & & & \\
\hline Detachment T2 & 3.82 & 0.52 & 3.31 & 0.70 & Time & .002 & .20 & 1.004 \\
\hline Detachment T3 & 3.79 & 0.85 & 3.31 & 0.98 & Group $\times$ Time & .263 & .04 & \\
\hline WLB T1 & 4.02 & 1.02 & 3.69 & 1.21 & $F(1.4,43.52)$ & & & \\
\hline WLB T2 & 4.41 & 0.86 & 4.11 & 0.90 & Time & .042 & .11 & 0.706 \\
\hline WLB T3 & 4.42 & 0.93 & 3.99 & 1.10 & Group $\times$ Time & .836 & .00 & \\
\hline
\end{tabular}

results showed that empathy did not predict coaching satisfaction ( $p=.080$ ) but empathy did predict goal attainment $(p=.004)$ in the "high intervention fidelity" group IG1. It explained $38 \%$ of the variance in goal attainment, $R^{2}=.38$, $F(1,16)=11.37, p=.004$.

Table 1 shows the descriptive statistics and correlations of coaches' empathy, ATI, spousal support, result-oriented self-reflection, positive affect and general outcome variables. Tables 2 and 3 show the results of the simple linear regression analyses of coaches' empathy, ATI, spousal support, result-oriented self-reflection, positive affect on coaching satisfaction and goal attainment 4 months after the coaching ended in IG1 and IG2.

Our second to fifth hypotheses (H2-H5) stated that client's ATI, spousal support during coaching, result-oriented self-reflection and positive affect predict coaching outcomes when coaches demonstrate high intervention fidelity. The results of the simple linear regression analyses with participants in IG1 suggested that ATI significantly predicted coaching satisfaction $(p=.005)$ and goal attainment $(p=.006)$. It explained $36 \%$ of the variance in coaching satisfaction, $R^{2}=.36, F(1,16)=10.68, p=.005$, and $35 \%$ of the variance in goal attainment, $R^{2}=.35, F(1,16)=10.2$, $p=.006$, supporting Hypothesis 2. Spousal support during coaching predicted coaching satisfaction $(p=.000)$ and goal attainment $(p=.006)$. It explained $54 \%$ of the variance in coaching satisfaction scores, $R^{2}=.54, F(1,16)=21.03$, $p=.000$, and $34 \%$ of the variance in goal attainment scores, $R^{2}=.34, F(1,16)=9.79, p=.006$, supporting Hypothesis 3 . Self-reflection significantly predicted coaching satisfaction $(p=.018)$ and goal attainment $(p=.036)$. It explained $27 \%$ of the variance in coaching satisfaction, $R^{2}=.27$, $F(1,15)=7.01, p=.018$, and $21 \%$ of the variance in goal attainment, $R^{2}=.21, F(1,15)=5.29, p=.036$, supporting Hypothesis 4. Positive affect predicted coaching satisfaction $(p=.033)$ and goal attainment $(p=.002)$. It explained $21 \%$ of the variance in coaching satisfaction, $R^{2}=.21$, $F(1,16)=5.42, p=.033$, and $42 \%$ of the variance in goal attainment scores, $R^{2}=.42, F(1,16)=13.2, p=.002$, supporting Hypothesis 5.

Hypotheses 6 and 7 (H6 and H7) stated that clients will show an increase in detachment and WLB over time in IG1, i.e., when coaches deliver the intervention as intended, in contrast to clients in IG2, whose coaches demonstrate low intervention fidelity. Table 4 shows the means, standard deviations, and repeated ANOVA statistics for detachment and WLB. Repeated measures ANOVA with a Greenhouse-Geisser correction determined that mean detachment levels showed a statistically significant difference between the measurements, $F(1.60,49.73)=7.80$, 
$p=.002$, partial $\eta^{2}=.20, d=1.004$. There was no interaction effect group $\times$ time, $F(1.60,49.73)=1.36, p=.263$. The detachment level at T1 $(M=3.12, S D=0.89)$ showed a significant difference from the mean detachment level at T2 $(M=3.58, S D=0.66)(p=.000)$ and at T3 $(M=3.56$, $S D=0.93)(p=.001)$. Hypothesis 6 was not supported. A repeated-measures ANOVA with a Greenhouse-Geisser correction determined that mean WLB levels showed a statistically significant difference between the measurements, $F(1.40,43.52)=3.86, p=.042$, partial $\eta^{2}=.11$, $d=0.706$. There was no interaction effect group $\times$ time, $F(1.40,43.52)=0.10, p=.836$. WLB at T1 $(M=3.86$, $S D=1.11)$ showed a significant difference from the mean WLB level at T2 $(M=4.27 ., S D=0.88)(p=.036)$ and at T3 $(M=4.21$., $S D=1.02)(p=.051)$. Hypothesis 7 was also not supported.

\section{Discussion}

Detaching from work and creating a satisfying WLB are increasing challenges for many people due to the trends of digitalization, home office and the associated blurring of work-life boundaries. Effective interventions to promote detachment and WLB are needed and, most importantly, we need to understand 'what works for whom in which circumstances' (Nielsen and Miraglia 2017). We therefore studied the contexts, processes and mechanisms that impact the effectiveness of the blended coaching with an extreme target group when it comes to detachment and blurring work-life boundaries since ever: SBOs and their spouses, who often work together in their business as work-linked couples. We focused on the under investigated coaches' behavior regarding intervention fidelity and empathy. We used the adapted design approach and examined two intervention groups that were formed according to the extent of coaches' intervention fidelity. As general coaching outcomes, we studied coaching satisfaction and goal attainment. Further, we distinguished proximal and distal intervention-specific outcomes, i.e., intervention receipt as the immediate target of the intervention, detachment and WLB as more distal outcomes. We conceptually based the coaching on the spousal influence on goal-setting and behavior change toward detachment and WLB, the result-oriented coaching concept and the neuroscientific ZRM. We tested the hypothesized mechanisms of change, i.e., spousal support during coaching, result-oriented self-reflection and positive affect. The results showed that clients' intervention receipt was significantly higher in the "high intervention fidelity" group than in the "low intervention fidelity" group $(p=.000)$. Only in the "high intervention fidelity" group, ATI and the hypothesized mechanisms of change of the couple coaching predicted general coaching outcomes 4 months after the in- tervention ended ( $p=.000$ to $p=.036$ ). The empathy of the coach predicted goal attainment $(p=.004)$ only in the "high intervention fidelity" group. Two-factor ANOVAs with repeated measures showed significant large to middle-sized effects on detachment $(p=.002)$ and WLB $(p=.042)$ over 8 months without any interaction effect. In the following paragraphs, we first discuss coaches' intervention fidelity and empathy and then we discuss the context of SBOs and their spouses, ATI and the mechanisms of change of this coaching concept.

\subsection{Coaches' Intervention Fidelity Matters!}

The hypothesized mechanisms of change of the coaching intervention predicted coaching satisfaction and goal attainment 4 months after the intervention ended only in the "high intervention fidelity" group. The immediate target of the intervention, the intervention receipt, was significantly higher in the "high intervention fidelity" group than in the "low intervention fidelity" group, indicating intervention fidelity matters and guides our understanding under which circumstances SBOs and their spouses comprehend and use the intervention skills during the coaching, being engaged and adherent with the content of the coaching and what makes clients more satisfied with the coaching and attain their coaching goals.

We followed in our study an inquiry in intervention research to carefully integrate coaches' behavior regarding intervention fidelity and to clearly describe intervention fidelity procedures. Interestingly, coaches' intervention fidelity was not stable within the coaching sessions and between the coaching sessions two and both sessions four and five. Sessions four and five were delivered significantly worse than session two. We decided to use the adapted design approach (Randall et al. 2005) and formed two intervention groups according to the extent of intervention fidelity in session two, in which the clients develop an attitude goal toward detachment and WLB as a core component of this coaching concept and the prerequisite for all the following sessions. Session two targets the "crossing of the Rubicon" from the motive to the intention by finding and setting self-congruent attitude goals with the method called the "inner team" (Schulz von Thun 2019). In session two, part six (goal formulation) was delivered in a significantly worse manner than all the other parts. We noticed that the coaches had problems helping the clients to formulate their attitude goal after exploring their motives with the "inner team" method. Part 5 (spousal support) was also not delivered as intended, on average. The coaches did not carefully stimulate spousal support in this phase. This provides us with hints for future studies, i.e., for revising the manual and for improving the training of the coaches. Intervention studies should integrate the measurement of 
coaches' behavior regarding intervention fidelity on a regular basis to help better interpret the study findings, revise manuals and train-the-coach workshops for future studies. Enhancing intervention fidelity has the effect of not only increasing internal validity but also increasing external validity, as a high degree of intervention fidelity is needed both for study replication and for the generalization of the interventions to other contexts (Borrelli et al. 2005).

\subsection{Coaches' Empathy Matters!}

We also observed coaches' behavior in regard to empathy, because coaching research underpins coaches' empathy as a coaching success factor and the need for observational data on coaches' actual empathic behavior (Will et al. 2016; Will and Kauffeld 2018). Coaches' empathy supports a strong working alliance in individual coaching settings (Baron and Morin 2009; de Haan et al. 2011), but working alliance did not seem to play a role in this couple format (Busch et al. 2021). Therefore, we had no hypothesis, but a research question about the role of coaches' empathy in this couple coaching concept. Our results showed that empathy predicted goal attainment 4 months after the coaching ended, but only in the "high intervention fidelity" group. We conclude that empathic behavior is vital for establishing a trusting coach-client relationship and essential for effective communication (Nicolai et al. 2007) not only for coaching in individual settings, but also in this couple coaching setting if the coaching intervention is delivered as intended by the authors.

\subsection{SBOs and Their Spouses Improved Their Detachment and WLB}

The results of our study show large effects for detachment $(d=1.0)$ and middle effects for WLB $(d=0.71)$, independent of coaches' behavior regarding intervention fidelity. These are impressive results in comparison to the results of the recent meta-analysis with 30 detachment intervention studies which showed small effects in increasing detachment $(d=0.36)$, on average (Karabinski et al. 2021). Therefore, we should consider the context in which we investigated the couple coaching intervention: successful, middle-aged SBOs in craft industry and their spouses, who often work together in their business as work-linked couples. They have blurred work-life boundaries (Helmle et al. 2014), show enormous difficulties to detach from their business (Kollmann et al. 2019) and are less likely to implement mental health promotion programs (Hogg et al. 2021), in particular when it comes to their own well-being and health (Busch et al. 2021). We successfully reached them with this coaching through people of trade guilds in their regional networks, to whom they have personal contact and trust
(Busch et al. 2021). There are several conceivable reasons why they may have profited so well from this coaching intervention. First and primary, the recent meta-analysis on detachment interventions (Karabinski et al. 2021) and previous intervention research (Clauss et al. 2018) stress that participants with higher levels of burnout or a stronger need for recovery show greater improvement than their less impaired counterparts. As SBOs have enormous problems to detach and to experience a satisfying WLB, and burnout is a significant concern for them (Shepherd et al. 2010), they may be more likely to benefit from the coaching in terms of their detachment and WLB regardless of coaches' intervention fidelity. In addition, participants in the "low intervention fidelity" group (IG2) worked significantly $(p=0.03)$ more hours per week $(50.5 \mathrm{hr}$ per week; male $59 \mathrm{hr}$; female $39 \mathrm{hr}$ ) on average than those in the "high intervention fidelity" group (IG1) (38.7 hr per week; male $50 \mathrm{hr}$; female $22 \mathrm{hr}$ ) on average. Experiencing high workload may increase the need for recovery, which may cause the effectiveness of the coaching in both intervention groups. Second, Karabinski et al. (2021) found that older employees benefit more from detachment interventions, as it might be the case as well for our participants, being 52 years on average. Third, the coaching experience itself, spending time with the spouse on reflecting and improving detachment experiences and WLB may be perceived as a pathway to distance oneself from work and ruminative thoughts. It may help the participants to detach and to be more satisfied with their WLB, independent how well the coach delivers the coaching.

\subsection{Effective Digital Health Interventions Need Clients with an Affinity for Technology Interaction}

The coaching was conceptualized as a blended intervention to benefit from digitalization, i.e., to give the participants more flexibility and decision latitude regarding when and where to take part in some parts of the coaching and to digitally support them between the sessions. We combined face-to-face sessions with tele-sessions, an online diary and online courses. The results showed that participants' ATI predicted coaching satisfaction and goal attainment only if the intervention was delivered by the coach as intended. This emphasizes that digital formats may positively influence the success of coaching interventions, especially if participants have a certain propensity for technology use, as has also been shown in online teaching (Backhaus et al. 2019). However, technology is not an end in itself: The relevance of the online elements needs to be clearly established by the coaches to obtain a positive effect. 


\subsection{Spousal Support During Coaching is the Mechanism of Change}

Our results show that spousal support during coaching is the mechanism of change that highly significantly predicts coaching satisfaction and goal attainment when coaches deliver the intervention as intended. Couple coaching builds on insights into the influence of spousal support on behavior changes and goal pursuit (Nowack 2017; Orehek and Forest 2016), on enhancing recovery experiences (Park \& Fritz 2015; Park and Haun 2017), and on WLB (Gudmunson et al. 2009; Helmle et al. 2014). The clients worked on their individual goals but were constantly encouraged by the coach to support each other. The couples experienced their interdependence during the coaching when setting and pursuing individual goals to enhance detachment and WLB (Hobfoll and Hobfoll 1994). We drew on the goal systems theory in relationship research (Orehek and Forest 2016) and the COR theory to argue that spousal support is the facilitating resource that helps partners set and pursue goals to enhance detachment and WLB. In the future, we may use the lens of WLB crafting (Dreyer and Busch 2021) to examine the processes by which spouses jointly develop strategies to enhance detachment and WLB.

\subsection{Limitations and Future Research Directions}

The present study has several limitations. First, our sample was limited to SBOs and their spouses in the German craft industry. Thus, we cannot expect SBOs from other industries and cultures to yield identical results. We need evaluation studies of coaching interventions with other, more diverse samples. Second, the small sample size and the dependencies of the data are strong limitations. The risk of statistical Type II errors is increased, and only small proportions of effects can be detected with small sample sizes (Semmer 2011). We need to conduct more intervention research with larger samples. Third, we observed coaches' behavior regarding intervention fidelity and empathy. Intervention fidelity was rather unstable within the sessions and across the sessions, in contrast to empathy. In the future, we should involve interaction analyses to investigate coaches' behavior in the interaction with clients' behavior (Ianiro et al. 2015). We may also improve our manual and trainthe-coach workshop to promote more stable behavior concerning intervention fidelity. Fourth, we used the adapted design (Randall et al. 2005) and the observed coaches' intervention fidelity to partition the participant sample into the two intervention groups, the "high intervention fidelity" group and the "low intervention fidelity" group. The differences in the results should therefore be due to the coaches' behavior in regard to intervention fidelity. However, it is the case that different coaches worked in the two intervention groups. Other behaviors beside intervention fidelity could have influenced the results. Fifth, the ZRM works with the somatic marker hypothesis to define and set self-congruent goals and actions. We assessed somatic markers through perceived positive affect after the first four coaching sessions. In the future, we could use bodily sensation maps. They reflect the most reliable and systematic consciously accessible bodily states during emotional processing (Nummenmaa et al. 2014). As online coaching is growing fast, future research should study effective online settings, tools and methods for online (couple) coaching and incorporate comparative studies between face-to-face, blended and purely online interventions to understand potential different processes and mechanisms "what works for whom in which circumstances' (Nielsen and Miraglia 2017) and guide practitioners to offer high-quality coachings.

\subsection{Practical Implications}

Our findings suggest that the blended couple coaching intervention effectively fosters detachment and WLB, but coaches should be aware not only of their empathy but also of the theoretical foundation and the core components of their coaching approach. We need carefully prepared manuals and train-the-coach workshops to support them in delivering high-quality coaching.

\section{Conclusions}

In the present study, we investigated coaches' behavior and the coaching mechanisms that impact the effectiveness of blended couple coaching to enhance detachment and WLB using an adapted design and mixed methods. We chose an extreme context in regard to detachment and WLB: SBOs and their spouses. Clients' ATI and the coaching mechanisms of change, i.e., spousal support during the coaching, result-oriented self-reflection, positive affect predicted coaching satisfaction and goal attainment four months after the coaching had ceased when coaches delivered the coaching as intended. Coaches' empathy predicted clients' goal attainment. The results showed large intervention effects on detachment and middle intervention effects on WLB 4 months after the coaching had ceased independent of coaches' behavior with regard to intervention fidelity. Our results suggest that coaches' intervention fidelity matters for activating the coaching mechanisms of change and for coaching outcomes. Coaches' empathy matters for clients' goal attainment.

Acknowledgements We have no known conflicts of interest to disclose. Our work is part of the www.e-RegioWerk.de project, which was funded by Grant 02L14A030 ff from the German Federal Institute for Education and Science. We thank all of our project cooperation part- 
ners, in particular Katja-Keller Landvogt, IKK classic. We thank all participating SBOs and their spouses, and all coaches. We also thank Georg Hensel, IKK classic, Peter Ropertz, KHS Rhein-Erft, Susanne und Andreas Drotleff, KHS Ortenau, Bernhard Ritter, KHS Freiburg, Dr. Thomas Günther, KHS Köln. We thank the psychology students Kim van den Anker, Teresa Martin Pelegrina and Jonas Riege for rating the videos.

Open Access This article is licensed under a Creative Commons Attribution 4.0 International License, which permits use, sharing, adaptation, distribution and reproduction in any medium or format, as long as you give appropriate credit to the original author(s) and the source, provide a link to the Creative Commons licence, and indicate if changes were made. The images or other third party material in this article are included in the article's Creative Commons licence, unless indicated otherwise in a credit line to the material. If material is not included in the article's Creative Commons licence and your intended use is not permitted by statutory regulation or exceeds the permitted use, you will need to obtain permission directly from the copyright holder. To view a copy of this licence, visit http://creativecommons.org/licenses/by/4. $0 /$.

\section{References}

Backhaus, J., Huth, K., Entwistle, A., Homayounfar, K., \& Koenig, S. (2019). Digital affinity in medical students influences learning outcome: a cluster analytical design comparing vodcast with traditional lecture. Journal of Surgical Education, 76(3), 711-719.

Baron, L., \& Morin, L. (2009). The coach-coachee relationship in executive coaching: a field study. Human Resource Development Quarterly, 20(1), 85-106. https://doi.org/10.1002/hrdq.20009.

Behrendt, P., \& Greif, S. (2018). Erfolgsfaktoren im Coachingprozess. In Handbuch Schlüsselkonzepte Im Coaching (pp. 163-172). https://doi.org/10.1007/978-3-662-49483-7 81.

Bennett, A.A., Bakker, A.B., \& Field, J.G. (2018). Recovery from work-related effort: a meta-analysis. Journal of Organizational Behavior, 39(3), 262-275. https://doi.org/10.1002/job.2217.

Berninger-Schäfer (2018). Online Coaching. Springer.

de Bloom, J., Vaziri, H., Tay, L., \& Kujanpää, M. (2020). An identity-based integrative needs model of crafting: Crafting within and across life domains. Journal of Applied Psychology, 105(12), 1423-1446. https://doi.org/10.1037/ap10000495

Borrelli, B., Sepinwall, D., Bellg, A. J., Breger, R., DeFrancesco, C., Sharp, D. L., Ernst, D., Czajkowski, S., Levesque, C., Ogedegbe, G., Resnick, B., \& Orwig, D. (2005). A new tool to assess treatment fidelity and evaluation of treatment fidelity across 10 years of health behavior research. Journal of Consulting and Clinical Psychology, 73(5), 852-860. https://doi.org/10.1037/0022-006X. 73.5.852.

Bryman, A. (2006). Integrating quantitative and qualitative research: how is it done? Qualitative Research, 6(1), 97-113. https://doi. org/10.1177/1468794106058877.

Busch, C \& Dreyer, R. (2020). Gesundheitscoaching für Paare. Springer. https://doi.org/10.1007/978-3-658-29852-4

Busch, C., Dreyer, R., \& Janneck, M. (2021). Blended recovery and burnout coaching for small-business copreneurs. Consulting Psychology Journal: Practice and Research, 73(1), 65-87. https:// doi.org/10.1037/cpb0000198

Carlson, D. S., \& Frone, M. R. (2003). Relation of behavioral and psychological involvement to a new four-factor conceptualization of work-family interference. Journal of Business and Psychology, 17(4), 515-535. https://doi.org/10.1023/A:1023404302295.

Clauss, E., Hoppe, A., O’Shea, D., González Morales, M. G., Steidle, A., \& Michel, A. (2018). Promoting personal resources and reducing exhaustion through positive work reflection among caregivers. Journal of Occupational Health Psychology, 23(1), 127-140. https://doi.org/10.1037/ocp0000063.

Cooper, A., Reimann, R., \& Dubberly, H. (2003). About face 2.0: The essentials ofinteraction design. Wiley.

Damásio, A. (1998). The somatic marker hypothesis and the possible functions of the prefrontal cortex. In A. C. Roberts, T. W. Robbins, \& L. Weiskrantz (Eds.), The prefrontal cortex: Executive and cognitive functions (pp. 36-50). Oxford University Press.

Deci, E. L., \& Ryan, R. M. (2012). Self-determination theory in health care and its relations to motivational interviewing: a few comments. International Journal of Behavioral Nutrition and Physical Activity, 9, 1-6. https://doi.org/10.1186/1479-5868-9-24.

Dreyer, R., \& Busch, C. (2021). At the heart of family businesses: how copreneurs craft work-life balance. Journal of Family Business Management. https://doi.org/10.1108/JFBM-12-2020-0113

European Commission. (2020). What is an SME? https://ec.europa.eu/ growth/smes/business-friendly-environment/sme-definition_e

Franke, T., Attig, C., \& Wessel, D. (2019). A personal resource for technology interaction: Development and validation of the Affinity for Technology Interaction (ATI) Scale. International Journal of Human- Computer Interaction, 35(6), 456-467. https://doi.org/ 10.1080/10447318.2018.1456150

Gearing, R.E., El-Bassel, N., Ghesquiere, A., Baldwin, S., Gillies, J., \& Ngeow, E. (2011). Major ingredients of fidelity: a review and scientific guide to improving quality of intervention research implementation. Clinical Psychology Review, 31(1), 79-88. https:// doi.org/10.1016/j.cpr.2010.09.007.

Gerhardt, C., Stocker, D., Looser, D., grosse Holtforth, M., \& Elfering, A. (2019). Well-being and health-related interventions in smalland medium-sized enterprises: a meta-analytic review. Zeitschrift Für Arbeitswissenschaft, 73(3), 285-294. https://doi.org/10.1007/ s41449-019-00154-1. Wohlbefindens- und gesundheitsbezogene Interventionen in kleinen und mittelgroßen Unternehmen: ein meta-analytisches Review.

Grant, A. M. (2003). The impact of life coaching on goal attainment, metacognition and mental health. Social Behavior and Personality, 31(3), 253-264. https://doi.org/10.2224/sbp.2003.31.3.253.

Grant, A.M., \& O'Connor, S. A. (2018). Broadening and building solution-focused coaching: feeling good is not enough. Coaching, 11(2), 165-185. https://doi.org/10.1080/17521882.2018. 1489868

Grant, A. M., Franklin, J., \& Langford, P. (2002). The self-reflection and insight scale: a new measure of private self-consciousness. Social Behavior and Personality, 30(8), 821-836. https://doi.org/ 10.2224/sbp.2002.30.8.821.

Greif, S. (2007). Coaching outcomes. International Coaching Psychology Review, 2(3), 222-249.

Greif, S. (2008). Coaching und ergebnisorientierte Selbstreflexion. Hogrefe.

Greif, S. (2017). Researching outcomes of coaching. In T. Bachkirova, G. B. Spence \& D. Drake (Eds.), The SAGE handbook of coaching (pp. 569-588). SAGE.

Greif, S., \& Berg, C. (2011). Result-oriented self-reflection-Report on the construct validation of theory-based scales. University of Osnabruck.

Gudmunson, C. G., Danes, S. M., Werbel, J. D., \& Loy, J. T. C. (2009). Spousal support and work-family balance in launching a family business. Journal of Family Issues, 30(8), 1098-1121. https://doi. org/10.1177/0192513X09333758.

de Haan, E., Culpin, V., \& Curd, J. (2011). Executive coaching in practice: what determines helpfulness for clients of coaching? Personnel Review, 40, 24-44. https://doi.org/10.1108/ 00483481111095500

Hasle, P., \& Limborg, H. J. (2006). A review of the literature on preventive occupational health and safety activities in small enterprises. Industrial Health, 44(1), 6-12. https://doi.org/10.2486/indhealth. 44.6. 
Haun, V. C., Haun, S., \& Himmel, T. (2017). Benefits and drawbacks of partner social support in dual earner couples' psychological detachment from work. Wirtschaftspsychologie, 24(3), 51-63.

Helmle, J. R., Botero, I. C., \& Seibold, D. R. (2014). Factors that influence perceptions of work-life balance in owners of copreneurial firms. Journal of Family Business Management, 4(2), 110-132. https://doi.org/10.1108/JFBM-06-2014-0013.

Hobfoll, S.E. (1989). Conservation of resources: a new attempt at conceptualizing stress. American Psychologist, 44(3), 513-524. https://doi.org/10.1037/0003-066X.44.3.513.

Hobfoll, S. E., \& Hobfoll, I. H. (1994). Work won't love you back. Freeman and Company.

Hogg, B., Medina, J. C., Gardoki-Souto, I., Serbanescu, I., Moreno-Alcázar, A., Cerga-Pashoja, A., Coppens, E., Tóth, M.D., Fanaj, N., Greiner, B. A., Holland, C., Kõlves, K., Maxwell, M., Qirjako, G., de Winter, L., Hegerl, U., Pérez-Sola, V., Arensman, E., \& Amann, B.L. (2021). Workplace interventions to reduce depression and anxiety in small and medium-sized enterprises: a systematic review. Journal of Affective Disorders, 290, 378-386. https:// doi.org/10.1016/j.jad.2021.04.071.

Howarth, A., Quesada, J., Silva, J., Judycki, S., \& Mills, P. R. (2018). The impact of digital health interventions on health-related outcomes in the workplace: a systematic review. Digital Health, 4, 205520761877086. https://doi.org/10.1177/2055207618770861.

Ianiro, P.M., Lehmann-Willenbrock, N., \& Kauffeld, S. (2015). Coaches and clients in action: a sequential analysis of interpersonal coach and client behavior. Journal of Business and Psychology, 30(3), 435-456. https://doi.org/10.1007/s10869014-9374-5.

Jurik, N.C., Kř́̌žková, A., Pospíšilová, M., \& Cavender, G. (2019). Blending, credit, context: doing business, family and gender in Czech and US copreneurships. International Small Business Journal: Researching Entrepreneurship, 37(4), 317-342. https://doi. org/10.1177/0266242618825260.

Karabinski, T., Haun, V.C., Nübold, A., Wendsche, J., \& Wegge, J. (2021). Interventions for improving psychological detachment from work: A meta-analysis. Journal of Occupational Health Psychology, 26(3), 224-242. https://doi.org/10.1037/ocp0000280

Kirkpatrick, D.L. (1976) Evaluation of Training. In R.L. Craig (Ed.), Training and Development Handbook: A Guide to Human Resource Development. McGraw Hill.

Kollmann, T., Stöckmann, C., \& Kensbock, J.M. (2019). I can't get no sleep-The differential impact of entrepreneurial stressors on work-home interference and insomnia among experienced versus novice entrepreneurs. Journal of Business Venturing, 34(4), 692-708. https://doi.org/10.1016/j.jbusvent.2018.08.001.

Koo, T. K., \& Li, M. Y. (2016). A guideline of selecting and reporting Intraclass correlation coefficients for reliability research. Journal of Chiropractic Medicine, 15(2), 155-163. https://doi.org/10. 1016/j.jcm.2016.02.012.

Krohne, H. W., Egloff, B., Kohlmann, C.-W., \& Tausch, A. (1996). Untersuchungen mit einer deutschen Version der "Positive and Negative Affect Schedule" (PANAS) [German version of the "Positive and Negative Affect Schedule" (PANAS)]. Diagnostica, 42(2), 139-156. https://doi.org/10.1037/t49650-000

Kuhl, J., Quirin, M., \& Koole, S.L. (2015). Being someone: the integrated self as a neuropsychological system. Social and Personality Psychology Compass, 9(3), 115-132. https://doi.org/10.1111/ spc3.12162.

McCoy, K., Stinson, K., Scott, K., Tenney, L., \& Newman, L.S. (2014). Health promotion in small business: a systematic review of factors influencing adoption and effectiveness of worksite wellness programs. Journal of Occupational and Environmental Medicine, 56(6), 579-587. https://doi.org/10.1097/JOM. 0000000000000171.Health.
McGraw, K. O., \& Wong, S.P. (1996). Forming inferences about some Intraclass correlation coefficients. Psychological Methods, 1(1), 30-46. https://doi.org/10.1037/1082-989X.1.1.30.

Meinecke, A. L., \& Kauffeld, S. (2019). Engaging the hearts and minds of followers: leader empathy and language style matching during appraisal interviews. Journal of Business and Psychology, 34(4), 485-501. https://doi.org/10.1007/s10869-018-9554-9.

Murphy, S.L., \& Gutman, S. A. (2012). Intervention fidelity: a necessary aspect of intervention effectiveness studies. American Journal of Occupational Therapy, 66(4), 387-388. https://doi.org/10. 5014/ajot.2010.005405.

Nicolai, J., Demmel, R., \& Hagen, J. (2007). Rating scales for the assessment of empathic communication in medical interviews (REM): Scale development, reliability, and validity. Journal of Clinical Psychology in Medical Settings, 14(4), 367-375. https:// doi.org/10.1007/s10880-007-9081-8.

Nielsen, K., \& Miraglia, M. (2017). What works for whom in which circumstances? On the need to move beyond the 'what works?' question in organizational intervention research. Human Relations, 70(1), 40-62. https://doi.org/10.1177/0018726716670226.

Nielsen, K., \& Randall, R. (2013). Opening the black box: presenting a model for evaluating organizational-level interventions. European Journal of Work and Organizational Psychology, 22(5), 601-617. https://doi.org/10.1080/1359432X.2012.690556.

Nowack, K. (2017). Facilitating successful behavior change: Beyond goal setting to goal flourishing. Consulting Psychology Journal: Practice and Research, 69(3), 153-171. https://doi.org/10.1037/ cpb0000088

Nummenmaa, L., Glerean, E., Hari, R., \& Hietanen, J. K. (2014). Bodily maps of emotions. Proceedings of the National Academy of Sciences, USA, USA of the United States ofAmerica, 111(2), 646-651. https://doi.org/10.1073/pnas.1321664111

Oettingen, G., \& Reininger, K. M. (2016). The power of prospection: mental contrasting and behavior change. Social and Personality Psychology Compass, 10(11), 591-604. https://doi.org/10.1111/ spc3.12271.

Orehek, E., \& Forest, A.L. (2016). When people serve as means to goals: implications of a motivational account of close relationships. Current Directions in Psychological Science. https://doi. org/10.1177/0963721415623536.

Park, Y. A., \& Haun, V.C. (2017). Dual-earner couples' weekend recovery support, state of recovery, and work engagement: worklinked relationship as a moderator. Journal of Occupational Health Psychology, 22(4), 455-466. https://doi.org/10.1037/ ocp0000045.

Park, Y. A., \& Fritz, C. (2015). Spousal recovery support, recovery experiences, and life satisfaction crossover among dual-earner couples. Journal of Applied Psychology, 100(2), 557-566. https://doi. org/10.1037/a0037894.

Pawson, R., \& Tilley, N. (1997). Realistic evaluation. Sage Publications, Inc.

Randall, R., Griffiths, A., \& Cox, T. (2005). Evaluating organizational stress-management interventions using adapted study designs. European Journal of Work and Organizational Psychology, 14(1), 23-31.

Schueller, S. M., Tomasino, K. N., \& Mohr, D.C. (2017). Integrating human support into behavioral intervention technologies: the efficiency model of support. Clinical Psychology: Science and Practice, 24(1), 27-45. https://doi.org/10.1111/cpsp.12173.

Schulz von Thun, F. (2019). Miteinander reden 3 (28. Auflage). rororo.

Semmer, N.K. (2011). Job stress intervention and organization of work. In J. C. Quick \& L.E. Tetrick (Eds.), Occupational health psychology (pp. 299-318). American Psychological Association.

Shepherd, C.D., Miles, M.P., Marchisio, G., Morrish, S.C., \& Deacon, J.H. (2010). Entrepreneurial burnout: exploring antecedents, dimensions and outcomes. Journal of Research in Marketing and Entrepreneurship, 12(1), 71-79. https://doi.org/10.1108/ 14715201011060894. 
Sonnentag, S. (2018). The recovery paradox: Portraying the complex interplay between job stressors, lack of recovery, and poor wellbeing. Research in Organizational Behavior, 38, 169-185. https:// doi.org/10.1016/j.riob.2018.11.002.

Sonnentag, S., \& Fritz, C. (2007). The recovery experience questionnaire: development and validation of a measure for assessing recuperation and unwinding from work. Journal of Ocсupational Health Psychology, 12(3), 204-221. https://doi.org/10. 1037/1076-8998.12.3.204.

Sonnentag, S., \& Fritz, C. (2015). Recovery from job stress: the stressordetachment model as an integrative framework. Journal of Organizational Behavior, 36, 72-103. https://doi.org/10.1002/ job.1924.

Spence, G. B. (2007). GAS powered coaching: goal attainment scaling and its use in coaching research and practice. International Coaching Psychology Review, 2(2), 155-167.

Steed, L.B., Swider, B.W., Keem, S., \& Liu, J.T. (2021). Leaving work at work: a meta-analysis on employee recovery from work. Journal of Management, 47(4), 867-897. https://doi.org/10.1177/ 0149206319864153.

Stephan, U. (2018). Entrepreneurs' mental health and well-being: a review and research agenda. Academy of Management Learning and Education, 17(3), 290-322. https://doi.org/10.5465/amp. 2017.0001.

Storch, M. (2004). Resource-activating selfmanagement with the zurich resource model (ZRM). European Psychotherapy, 1(5), $27-64$.

Storch, M., \& Krause, F. (2017). Selbstmanagement-ressourcenorientiert: Grundlagen und Trainingsmanual für die Arbeit mit dem Züricher Ressourcen Modell (ZRM). Hogrefe.
Syrek, C., Bauer-Emmel, C., Antoni, C., \& Klusemann, J. (2011). Entwicklung und validierung der trierer kurzskala zur messung von work-life balance (TKS-WLB). Diagnostica, 57(3), 134-145. https://doi.org/10.1026/0012-1924/a000044

Watson, D., Clark, L. A., \& Tellegen, A. (1988). Development and validation of brief measures of positive and negative affect: The PANAS scales. Journal of Personality and Social Psychology, 54(6), 1063-1070. https://doi.org/10.1037/0022-3514.54.6.1063

Will, T., \& Kauffeld, S. (2018). Relevanz von Empathie für dyadische Beziehungen - Über ein unterschätztes Konstrukt in der CoachKlienten-InteraktionRelevance of Empathy for Dyadic Relations - About an Underestimated Construct in the Coach-ClientInteraction. Coaching I Theorie \& Praxis, 4(1), 45-54. https:// doi.org/10.1365/s40896-018-0023-2.

Will, T., Gessnitzer, S., \& Kauffeld, S. (2016). You think you are an empathic coach? Maybe you should think again. The difference between perceptions of empathy vs. empathic behaviour after a person-centred coaching training. Coaching, 9(1), 53-68. https://doi.org/10.1080/17521882.2016.1143023.

Yoder, P., \& Symons, F. (2010). Observational measurement of behavior. Springer.

Publisher's Note Springer Nature remains neutral with regard to jurisdictional claims in published maps and institutional affiliations. 